\title{
Risk Factors for Neonates with Hyperbilirubinemia
}

\author{
J Hepsi Bai ${ }^{1 *}$ and Annie Mathew ${ }^{2}$ \\ ${ }^{1}$ Assistant Professor, the Salvation Army Catherine Booth College of Nursing, India \\ ${ }^{2}$ Department of Child Health Nursing, Kerala University of Health Sciences, India
}

Received: December 18, 2017; Published: January 05, 2018

*Corresponding author: J Hepsi Bai, Assistant Professor, the Salvation Army Catherine Booth College of Nursing, Nagercoil, Tamil Nadu, India; Tel: 7867073380; Email: hepsijoseph@gmail.com

\begin{abstract}
Neonatal jaundice is a common condition that pediatricians encounter in their practice. A descriptive study was conducted to assess the risk factors for neonates with hyperbilirubinemia at Sree Gokulam Medical College Hospital, Trivandrum. Using consecutive sampling technique quantitative data was collected from 110 neonates diagnosed with hyperbilirubinemia and undergone phototherapy in Neonatal units and OBG wards. Pretested and validated questionnaire was used to collect the data. The results showed that both neonatal (ABO incompatibility, Rh incompatibility, cord bilirubin level, hypoglycemia, caput succedenum) and maternal clinical variables (previous child with history of hyperbiliruibinemia, gestational diabetes mellitus, oxytocin use) had acted as risk factors for neonates with hyperbilirubinemia.
\end{abstract}

Key words: Risk Factors; Neonates; Hyperbilirubinemia; Clinical Variables

\section{Introduction}

Neonatal jaundice is a common condition that pediatricians encounter in their practice. It is also a significant cause of neonatal morbidity world-wide and is estimated to be present in $60 \%$ of term neonates and $80 \%$ of preterm babies. Interventions to prevent progression of neonatal jaundice significantly reduce the morbidity and mortality rate of neonate [1]. Elevated serum bilirubin can damage neurons and for this reason it is measured in the neonate with obvious jaundice or signs of underlying disease [1]. Data derived from risk instruments that incorporate several factors, support the potential multifactorial etiopathogenesis of marked hyperbilirubinemia; albeit genetic contributors may go undetected and individual factors confer different degrees of risk.

\section{Methodology}

A descriptive study was conducted to assess the risk factors of neonates with hyperbilirubinemia at Sree Gokulam Medical College Hospital, Trivandrum. Using consecutive sampling technique quantitative data was collected from 110 neonates diagnosed with hyperbilirubinemia and undergone phototherapy in Neonatal units and OBG wards. Pretested and validated questionnaire and checklist was used to collect the data. Permission was obtained from institutional research committee and institutional authority. Collected data were analyzed using SPSS-18; descriptive analysis was done to know the empirical information on neonates with hyperbilirubinemia.

\section{Results and Discussion}

More than half (53.6\%) of the neonates received phototherapy were males, majority of the neonates $(79.10 \%)$ were classified as term according to gestational age, $(81.8 \%)$ were classified as normal birth weight, (83.6\%) were classified as appropriate for gestational age. More than one fourth of the neonates (31.8\%) had ABO incompatibility, 9.1\% had Rh incompatibility and $4.5 \%$ had both Rh incompatibility and ABO incompatibility. Nearly quarter of the neonates (21.80\%) had cord bilirubin level > $2.5 \mathrm{mg} \% .9 .1 \%$ of neonates had hypoglycemia as postnatal complication. More than quarter of the neonates had caput succedenum (25.5\%), (39.1\%) developed yellowish discoloration (physiological jaundice) on third (49 to 72 hours) postnatal day. A large majority of the neonates $(80.9 \%)$ received phototherapy for $<24$ hours and nearly half of the neonates $(44.5 \%)$ were in high risk zone as per nomogram designation of risk zone category for receiving phototherapy procedure. more than half of the neonates $(68.2 \%)$ received direct breast feeding after birth. More than three fourth of the neonates $(76 \%)$ received demand breast feeding before diagnosing hyperbilirubinemia. There was a progressive declination of bilirubin level to normal range after initiating phototherapy from day 0 to day 2 .

Regarding the maternal variables of neonates with hyperbilirubinemia, it was found that nearly three fourth of the 
neonates mothers $(66.4 \%)$ were primi. More than half $(59.5 \%)$ of the multi parity mothers mentioned that their previous child had history of receiving phototherapy. Nearly one fourth of the mothers (14.5\%) had GDM (gestational diabetes mellitus). Singh $\mathrm{M}$ has stated that gestational diabetes mellitus is a maternal risk factor for the neonate to develop jaundice [1]. More than half of the mothers $(60.9 \%)$ received oxytocin derivatives during intranatal period. This finding is consistent with study findings by [2]. That the mean total and direct bilirubin levels were higher in neonates delivered using oxytocin $(0.4 \pm 0.1$ and $17.99 \pm 0.4$, respectively $)$, compared to those without oxytocin induction $(0.383 \pm 0.1$ and $16.2 \pm 0.28$, respectively) ( $p=0.001)$. More than half of the mothers $(66.4 \%)$ had normal vaginal delivery. The present study finding is consistent with findings by [2], that the mean total bilirubin level was significantly higher in newborns delivered per vaginally (17.3 $\pm 3.5 \mathrm{mg} / \mathrm{dl})$, compared to cases born by cesarean section (16.1 \pm $3.9 \mathrm{mg} / \mathrm{dl})(\mathrm{p}=0.02)$ [2].

\section{Conclusion}

The study has identified various risk factors and variables related to mother and neonates with hyperbilirubinemia. Detection of risk factors by the neonatal health team early in the mother and neonate can protect and prevent the neonate from mortality of hyperbilirubinemia.

\section{References}

1. Singh M (2010) Care of the newborn.

2. Garosi E, Mohammadi F, Ranjkesh F (2016) The relationship between neonatal jaundice and maternal and neonatal factors. Iranian Journal of Neonatology 7(1): 37-40.

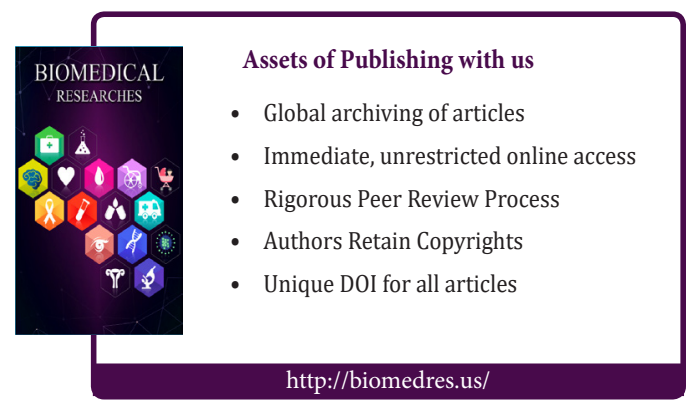

